\title{
LÍMITES A LOS DERECHOS DE OBTENCIÓN VEGETAL EN LA LEY FEDERAL DE VARIEDADES VEGETALES DE MÉXICO
}

\author{
CARLOS ERNESTO ARCUDIA HERNÁNDEZ*
}

\section{INTRODUCCIÓN}

Dentro de los profundos cambios que experimentó México en la década de los años ochenta y noventa del siglo pasado destaca la transformación del campo mexicano. Se pasó de un modelo basado en la intervención directa del Estado a una profunda liberalización. La crisis de los años ochenta fue, desde luego, financiera y monetaria e inmediatamente económica y productiva, pero también recogió y dio lugar a una dramática ruptura en el modo como acostumbraban relacionarse los grupos dirigentes del Estado con los grupos dominantes de la economía y la sociedad ${ }^{1}$.

La "regla de oro" del sistema mexicano empezó a conocer sus últimos tiempos. El reconocimiento de la presidencia mexicana como lugar de las decisiones de última instancia en la política y en la economía empezó a ser fuertemente cuestionado desde las propias cúspides de la empresa privada. La necesidad de corregir a fondo el régimen del presidencialismo autoritario heredado de la Revolución mexicana

\footnotetext{
* Doctor en Derecho Mercantil por la Universidad Complutense de Madrid. Profesor Investigador de Tiempo Completo de la Unidad Académica Multidisciplinaria Zona Huasteca de la Universidad Autónoma de San Luis Potosí. Investigador Nacional Nivel 1 del Sistema Nacional de Investigadores del conacyt. Correo electrónico: carlos.arcudia@ uaslp.mx; carlosarcudia@gmail.com. Autor de diversos artículos y capítulos de libro entre los que destaca "El régimen de protección jurídica de las obtenciones vegetales en México: Propuestas para una mejor adaptación al sistema cupov", en Revista La Propiedad Inmaterial n.o 19; "La élite del poder económico en México" en la Revista de Economía Crítica; "La participación de los inversores institucionales en el gobierno de las grandes sociedades" en la Revista de la Facultad de Contaduría y Administración de la UnAM; y, "La privatización y reestructuración de la banca en México", especial referencia a los aspectos legales en la Revista E Mercatoria. Fecha de recepción: 14 de septiembre de 2016. Fecha de aceptación: 30 de noviembre de 2016. Para citar el artículo: Arcudia Hernández, C. E. Límites a los derechos de obtención vegetal en la Ley Federal de Variedades Vegetales de México. Revista La Propiedad Inmaterial n. ${ }^{\circ} 22$, Universidad Externado de Colombia, julio-diciembre 2016, pp. 187-208. Dor: http://dx.doi.org/10.18601/16571959.n22.05

1 Cordera, Rolando y Tello, Carlos, 2010, La disputa por la Nación, México, Siglo XXI, p. 19.
} 
se volvió idea fuerza del reclamo democrático que hasta entonces habían protagonizado sobre todo diversos grupos populares ${ }^{2}$.

Para lograr este propósito, el gobierno sometió a la sociedad y a su aparato productivo, decaído pero todavía prácticamente intacto, y en parte ampliado y remozado gracias al auge petrolero, a un drástico ajuste externo y fiscal que tenía como objetivo principal, casi único, crear el excedente necesario para continuar pagando la deuda externa. Con ello -se pensaba en el gobierno- se podría regresar a los mercados de capital internacionales, para así recobrar el crecimiento económico que entonces no sólo se perdía como resultado de la crisis financiera sino de una decisión del Estado 3 .

El pobre desenvolvimiento del agro mexicano durante la década de 1980 fue uno de los fenómenos que contribuyeron a que se considere a estos años como la década perdida. En pesos constantes, el ritmo de crecimiento agropecuario no sobrepasó el $1.3 \%$ de 1980 a 1990 , aunque fue opuesto el comportamiento de sus dos componentes: la agricultura creció un 3.2\% y la ganadería decreció un $-2.7 \%{ }^{4}$.

A partir de los primeros años de la década de 1990 se definieron las acciones del Estado mexicano en materia de liberalización agropecuaria. Entre ellas destacan: la reforma ejidal; la eliminación de los permisos a la importación de alimentos y la negociación del TLCAN; el desmantelamiento y extinción de la Compañía Nacional de Subsistencias Populares, y con ello, de sus empresas e infraestructura de almacenamiento; la reducción de subsidios al agro (al crédito, a precios de los insumos y al consumo de tortilla, etc.) y a la abolición de los programas de extensión agrícola 5 .

Estos cambios drásticos en el modelo de desarrollo de la industria agrícola son de importancia teniendo en cuenta la estructura dicotómica y desigual de la industria agrícola en nuestro país. En efecto, en México coexisten esquemas tradicionales de producción de subsistencia -esto es, un medio rural anclado en el pasado histórico, que ya ha sido rebasado por los avances tecnológicos- $\mathrm{y}$, de otro lado, áreas productivas modernas y tecnificadas, en las que el viejo concepto de campesino ya no tiene lugar. Así, en México se dibujan claramente una agricultura campesina (o tradicional) y una agricultura comercial ${ }^{6}$.

4 Yúnez Naude, Antonio, "Las transformaciones del campo y el papel de las políticas públicas”, en Historia económica general de México, México, El Colegio de México, 2010, p. 472.

5 Ibíd., pp. 743-744

6 Coll-Hurtado, Atrántida y Godínez Calderón, María de Lourdes, La agricultura en México: un atlas en blanco y negro, México, Instituto de Geografía UnAm, 2003, p. 95. 


\section{LA PROTECCIÓN DE LA PROPIEDAD INDUSTRIAL SOBRE VARIEDADES VEGETALES EN MÉXICO}

\section{i.i. El Tratado de Libre Comercio para América del Norte}

Con el Tratado de Libre Comercio para América del Norte (TlCAN) México completó la liberalización de la agricultura y eliminó los márgenes de protección que el país había reservado en los compromisos para entrar al Acuerdo General sobre Aranceles y Comercio (GATT, por sus siglas en inglés). Las negociaciones del TLCAN han arrojado un balance no del todo favorable al sector agropecuario mexicano, toda vez que la solución de los conflictos de interés entre México y Estados Unidos, antagónicos en muchos aspectos, satisfizo más a este último. Y es que el antagonismo resulta de la que se considera la ventaja absoluta mexicana, su vecindad geográfica con Estados Unidos. Además de los problemas de vecindad, la agricultura mexicana enfrenta otro obstáculo: compite con la estadounidense en lugar de complementarla. En efecto, al estar ambos países situados en el hemisferio norte, los ciclos agrícolas son similares por la misma sucesión de estaciones climáticas. Por ende, México compite con Estados Unidos en casi todos los productos comercializables, especialmente en los más neurálgicos para la economía nacional: los granos, alimentos básicos de la producción ${ }^{7}$.

Los operadores del cambio de modelo de desarrollo consideraron que la liberalización debería elevar la productividad por cambios en la estructura productiva: mayor producción de frutas y hortalizas y contracción de granos y oleaginosas; menor empleo sectorial total, menos mano de obra y más tierras dedicadas a productos rentables; así como intercambio comercial con mayores importaciones de granos y oleaginosas y crecientes exportaciones ${ }^{8}$. En pocas palabras, fomentar la agricultura comercial en detrimento de la agricultura tradicional.

Pues bien, los resultados del TLCAN han arrojado un balance no del todo favorable al sector agropecuario mexicano, toda vez que México no se reservó márgenes de acción para compensar las diferencias en productividad que separan la agricultura mexicana de la estadounidense ni los efectos de los subsidios que el gobierno norteamericano otorga a sus productores agropecuarios ${ }^{9}$.

En materia de exportaciones agropecuarias se beneficia principalmente un segmento de la agricultura moderna dedicado a la producción de legumbres y hortalizas, plantas, flores y frutas, que representa el 77\% de las ventas foráneas. Las hortalizas, legumbres y frutas destinadas a Estados Unidos representan dos tercios de las ventas agropecuarias totales. Los beneficios del libre comercio exportador se han concentrado en un número reducido de productores, mientras que la mayoría

7 Puyana, Alicia y Romero, José, México, de la crisis de la deuda al estancamiento económico, México, El Colegio de México, 2009, pp. 166-167.

8 Ibíd., p. 164.

9 Ibíd., pp. 166-167. 
de los campesinos y agricultores o industrializadores de los productos primarios continúan dependiendo de un mercado interno de lento crecimiento e intensamente competido por abastecedores foráneos. El dualismo se acentúa, y también las disparidades entre las regiones prósperas y las rezagadas ${ }^{10}$.

Dentro de las transformaciones operadas por el TLCAN se encuentra la obligación de nuestro país de otorgar protección a las variedades vegetales. En efecto, en el capítulo XVII del TLCAN -al igual que ocurre en los Acuerdos sobre los Aspectos de Propiedad Intelectual Relacionados con el Comercio (ADPIC)- se recoge el compromiso de los Estados parte de "otorgar protección a las variedades de plantas mediante un esquema efectivo de protección sui géneris o ambos".

Pero el TLCAN -a diferencia del Acuerdo ADPIC- impone a México dos obligaciones más. En primer lugar, el inciso a) de su artículo 1701.3 establece que México realizará su mayor esfuerzo por cumplir lo antes posible con las disposiciones sustantivas del cupov 1978 o 1991. Y lo deberá hacer antes del término de dos años contados a partir de la fecha de firma del TLCAN.

En segundo lugar, el inciso b) del mismo artículo 1701.3 dispone que México aceptará, a partir de la fecha de entrada en vigor del TLCAN, solicitudes de los obtentores de vegetales para proteger variedades en todos los géneros y especies y concederá protección conforme a tales disposiciones sustantivas con celeridad después de cumplir el inciso a).

Esta obligación se cumplió con la adhesión de México al Convenio de la Unión Internacional para la Protección de las Obtenciones Vegetales (cupov) y la adopción en 1996 de la Ley Federal de Variedades Vegetales (en adelante, LFvV). Ahora bien, la normativa contenida en el TLCAN tiene un claro sesgo hacia la agricultura comercial de carácter exportador.

Pues bien, llegados a este punto se está en posibilidad de plantear el problema que representa la protección de la propiedad industrial en la agricultura y la necesidad de regular adecuadamente sus límites. Como ya quedó asentado, nuestro país tiene una agricultura dicotómica y desigual. Por un lado, la agricultura campesina, por el otro, la agricultura comercial. El nuevo modelo de desarrollo agropecuario prima a la agricultura comercial sobre la campesina. El TLCAN busca favorecer a la agricultura comercial, que, por lo demás, tampoco resultó tan beneficiada como se esperaba por la apertura comercial.

La introducción de derechos de propiedad industrial sobre variedades vegetales puede representar un duro golpe para la industria agrícola campesina. Ahora bien, puede no ser tan benéfica para la agricultura comercial si no se tiene cuidado en limitar los derechos que otorgan los títulos de obtención vegetal. A este respecto se puede anticipar que el sistema Cupov -adoptado en México- ofrece una regulación de la propiedad industrial más leve que el sistema de patentes. Es precisamente

10 Ibarra Muñoz, David, Ensayos sobre economía Mexicana, México, fCe, 2015, pp. 364-366. 
mediante los límites a los derechos de obtención como se trata de atenuar los efectos desfavorables en la industria agrícola.

En el presente trabajo se abordará el estudio de los límites a los derechos de obtención vegetal en la LFVV y se harán propuestas de reforma legal para que respondan mejor a las necesidades de la agricultura mexicana. Lo anterior, haciendo uso de las opciones que el propio cupov les da a sus países miembros. Como primer paso, se expondrá brevemente el régimen jurídico contenido en la LFVV.

\section{i.2. La Ley Federal de Variedades Vegetales}

$\mathrm{Al}$ igual que sucede en el ámbito europeo, la LFVV separa materias y regula exclusivamente el derecho del obtentor. Otras legislaciones americanas tratan conjuntamente, en una misma norma, tanto el derecho del obtentor como la comercialización de semillas ${ }^{11}$. En México, la comercialización de semillas se encuentra regulada en una ley distinta de la LFvv: la Ley de Producción, Certificación y Comercio de Semillas de 2007. En punto a su contenido, la LFVv refleja los principios fundamentales del Acta del cupov de 1978. No obstante, es una ley verdaderamente endeble en el aspecto coercitivo. En concreto, no contiene mecanismos de aplicación coercitiva, ni para el resarcimiento de daños y perjuicios ocasionados por la violación de la misma ${ }^{12}$.

Si bien el Acta de 1978 del cupov eliminó la definición de variedad vegetal, la LFVV define a la variedad vegetal como una subdivisión de una especie que incluye a un grupo de individuos con características similares y que se considera estable y homogénea (art. 2 fracc. Ix). Desde nuestro punto de vista, la inclusión del concepto de variedad vegetal en la LFVV es un acierto porque sólo estableciendo el concepto de variedad vegetal se puede delimitar la frontera entre el sistema de patentes y el sistema de títulos de obtención vegetal ${ }^{13}$.

El artículo $7 \mathrm{LFVv}$ prevé el cumplimiento de cuatro requisitos sustantivos como condición para tener acceso a la protección por medio del título de obtentor. La LFVV exige que en la variedad vegetal que se pretende proteger mediante el título de obtentor estén presentes las siguientes condiciones: novedad, distintividad, estabilidad y homogeneidad. En el régimen de la LFVV, la novedad es equivalente a la ausencia de comercialización de la variedad vegetal a proteger. En efecto, el artículo 7 fracción I incisos a) y b) dispone que una variedad se tendría por nueva cuando a la fecha de presentación de la solicitud el material de reproducción no

11 Gattari, Carlos y Durante, Martha, "Comentarios sobre la Ley Federal de Variedades Vegetales de los Estados Unidos Mexicanos", en Temas de Derecho Industrial $y$ de la Competencia n.o 2, Buenos Aires, Ciudad Argentina, 1997, p. 301.

12 Becerra Ramírez, Manuel, "La ley Mexicana de Variedades Vegetales", Liber ad Honorem Sergio García Ramírez, México, unam, 1998, pp. 133-134.

13 Arcudia Hernández, Carlos, "El régimen de protección jurídica de las obtenciones vegetales en México: propuestas para una mejor adaptación al sistema cupov”, Revista La Propiedad Inmaterial n.o 19, 2015, p. 102. 
hubiera sido enajenado en más de un año anterior a esa fecha en el territorio nacional, o en cualquier otro país por más de seis años en caso de árboles y vides, y de cuatro años en el resto de las especies.

Tendrá la característica de la distintividad la variedad vegetal que se distinga técnica y claramente por uno o varios caracteres pertinentes de cualquiera otra variedad, cuya existencia sea conocida en el momento en que se solicite la protección. Dichos caracteres deberán reconocerse y describirse con precisión (art. 7 fracc. II LFVV). Será homogénea la variedad vegetal que sea suficientemente uniforme en sus caracteres pertinentes a reserva de la variación (art. 7 fracc. IV LFVV). Por último, será estable la variedad vegetal que conserve inalterados sus caracteres pertinentes después de reproducciones o propagaciones sucesivas (art. 7 fracc. III LFVV).

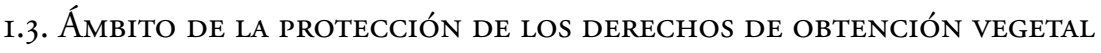 en la Ley Federal de Variedades Vegetales}

La variedad que cumpla con los requisitos anteriormente expuestos dará a sus obtentores los siguientes derechos plasmados en el artículo 4 LFVV. En la fracción I se establece una especie de "derecho moral" de ser reconocido como obtentor de una variedad vegetal. No sabemos si esta ocurrencia del legislador mexicano responde a su afán de reconocer el esfuerzo de los mejoradores de variedades vegetales, o bien a una confusión del derecho de las obtenciones vegetales con el de autor. En todo caso, esa disposición parece fuera de lugar ${ }^{14}$.

La fracción II del artículo 4 LFVV contiene el monopolio que le concede el Estado al obtentor. A saber, aprovechar y explotar, en forma exclusiva y de manera temporal, por sí o por terceros con su consentimiento, una variedad vegetal y su material de propagación, para su producción, reproducción, distribución o venta, así como para la producción de otras variedades vegetales e híbridos con fines comerciales. Estos derechos tendrán una duración de: a) Dieciocho años para especies perennes (forestales, frutícolas, vides, ornamentales) y sus portainjertos, y b) Quince años para las especies no incluidas en el inciso anterior. Estos plazos se contarán a partir de la fecha de expedición del título de obtentor y, una vez transcurridos, la variedad vegetal, su aprovechamiento y explotación pasarán al dominio público.

Por lo que se refiere al ámbito de la protección, la LFVv se sitúa en un punto intermedio entre las actas del cupov de 1978 y de 1991. En efecto, la LFVV concede al obtentor el derecho exclusivo de producir la variedad vegetal, cualquiera que sea su fin, así como el monopolio de la distribución de la variedad vegetal y de su comercialización, Por el contrario, no le concede la exclusiva para la preparación para la reproducción o la comercialización, la oferta en venta, la exportación ni la importación ${ }^{15}$.

15 Ibíd., p. 106. En el artículo 5 del Acta del cupov de 1978 el ámbito de protección 
Como se puede observar de la lectura del precepto, el obtentor tiene un derecho de exclusiva sobre su variedad vegetal en buena parte de la cadena de la obtención vegetal. El obtentor puede otorgar licencias a terceros para producir o sembrar su variedad. Pero eso se hace mediante una contraprestación en dinero. La agricultura comercial, fuertemente enfocada al mercado internacional, quizá pueda hacer frente a estos costos, pero la agricultura campesina no. El cupov, del cual México es parte, establece una serie de pautas para regular los límites de ese monopolio temporal en favor del obtentor para conseguir un equilibrio entre los distintos agentes de la industria agrícola. Antes de abordar los límites a los derechos de obtención vegetal se presenta, en la tabla 1, una síntesis del régimen jurídico de protección de las variedades vegetales en la LFVv.

TABLA I

SÍNTESIS DEL RÉGIMEN JURÍDICO DE LOS DERECHOS DEL OBTENTOR

\begin{tabular}{|c|c|c|}
\hline $\begin{array}{c}\text { Concepto de variedad } \\
\text { vegetal }\end{array}$ & $\begin{array}{l}\text { Requisitos para } \\
\text { obtener la protección }\end{array}$ & $\begin{array}{l}\text { Ámbito de protección del título } \\
\text { de obtención vegetal }\end{array}$ \\
\hline $\begin{array}{l}\text { La variedad vegetal es } \\
\text { una subdivisión de una } \\
\text { especie que incluye a } \\
\text { un grupo de individuos } \\
\text { con características simi- } \\
\text { lares y que se considera } \\
\text { estable y homogénea } \\
\text { (art. } 2 \text { fracc. IX LFVv). }\end{array}$ & $\begin{array}{l}\text { Novedad } \\
\text { Distintividad } \\
\text { Homogeneidad } \\
\text { Estabilidad (art. } 7 \\
\text { LFVv). }\end{array}$ & $\begin{array}{l}\text { Ser reconocido como el obtentor de la } \\
\text { variedad. } \\
\text { Monopolio temporal para aprovechar y } \\
\text { explotar, en forma exclusiva y de manera } \\
\text { temporal, por sí o por terceros con su } \\
\text { consentimiento, una variedad vegetal y su } \\
\text { material de propagación, para su produc- } \\
\text { ción, reproducción, distribución o venta, así } \\
\text { como para la producción de otras variedades } \\
\text { vegetales e híbridos con fines comerciales } \\
\text { (art. } 4 \text { LFvV). }\end{array}$ \\
\hline
\end{tabular}

\section{LÍMITES A LOS DERECHOS DE OBTENCIÓN VEGETAL ESTABLECIDOS en el Convenio de la Unión Internacional para la Protección de Obtenciones Vegetales}

El cupov establece límites a los derechos de obtención vegetal. El Convenio da un mayor o menor margen a los Estados miembros para implementarlos en sus legislaciones nacionales. Habida cuenta del panorama general de la agricultura mexicana que presentamos en los epígrafes anteriores, merece la pena un análisis

del derecho del obtentor se extiende a la producción con fines comerciales, la puesta a la venta y la comercialización del material de la variedad. En el Acta de 1991 el ámbito de protección se amplió considerablemente para cubrir toda la "cadena de la obtención vegetal”. Así las cosas, según el artículo 14 se requerirá autorización del obtentor para la producción o la reproducción de la variedad, la preparación a los fines de reproducción o de la multiplicación, la oferta en venta, la venta o cualquier otra comercialización, la exportación, la importación. 
profundo de las opciones que desde el propio cupov se conceden a los miembros con el objeto de salvaguardar los intereses nacionales sin detrimento de los legítimos derechos de los obtentores.

\section{I. LA EXCEPCIÓN DE EXPERIMENTACIÓN Y USO PRIVADO}

El artículo 15.1 inciso iii) del Acta del cupov de 1991 excluye de los derechos del obtentor los actos realizados con objeto de obtención de nuevas variedades, salvo que se trate de variedades esencialmente derivadas. Por tanto, no constituye un acto de infracción el uso de la variedad protegida para obtener una nueva, sino la comercialización de esa nueva variedad.

Los actos efectuados con fines privados, no comerciales o con propósitos de experimentación también están exentos ${ }^{16}$.

De igual manera, el artículo 17 del Acta del cupov de 1991 establece que el derecho del obtentor podrá limitarse por razones de interés público. Esta disposición, semejante a la contenida en el Acta del cupov de 1978, está concebida para evitar las críticas de aquellos que invocaban los graves riesgos que la concesión de un monopolio podría acarrear cuando la obtención vegetal protegida fuese una planta de las que producen víveres ${ }^{17}$.

Una de las notas características del sistema cupov es que se puede disponer libremente de las variedades protegidas para el desarrollo de nuevas variedades, lo que constituye el llamado privilegio del mejorador.

En el artículo 5.3 del Acta del cupov de 1961 se regulaba el privilegio del obtentor, según la cual no se requiere la autorización del titular de la variedad inicial para la creación de una nueva variedad con fines comerciales. Únicamente se requeriría esta autorización cuando la producción con fines comerciales exigiese el uso reiterado de la variedad inicial ${ }^{18}$.

16 El Acta del cupov de 1978 no contenía una previsión similar; por tanto, los actos de reproducción de la variedad protegida con el propósito de determinar sus características genotípicas y fenotípicas estaban permitidos con propósitos de experimentación. Lo que no se puede asegurar es si cubrían los actos de reproducción con el fín de desarrollar una nueva variedad vegetal. De cualquier forma, esa reproducción estará cubierta ahora en el artículo 15.1 inciso iii) del Acta del cupov de 1991. Ver Verma, Surinder, “Trips and Plant Variety Protection in Developing Countries", European Intellectual Property Review, vol, 16, n.o 6, 1995, p. 285.

17 Curto Polo, Mercedes, "La protección de las invenciones biotecnológicas (Especial referencia a la coexistencia de patentes y títulos específicos en relación a las obtenciones vegetales)", Revista General de Derecho, año Lıv, n.o 642, 1992, p. 2372. Estos preceptos se encuentran en clara relación con el artículo 52 LP que tiene su razón de ser en los fundamentos mismos del sistema de patentes puesto que - de este modo- se logra un equilibrio entre los intereses del inventor (consistentes en conseguir una adecuada retribución por su esfuerzo inventivo) y los de la generalidad (que se ven favorecidos por los avances logrados en el desarrollo tecnológico).

18 Roth, Benhard, "Current Problems in the Protection of Inventions in the Field of Plant Biotechnology. A position paper”, International Review of Intellectual Property and Competition Law, vol. 18, n..$^{1}$, 1987, p. 50. 
Con el desarrollo de las invenciones biotecnológicas, esta norma legal daba lugar a que los resultados de las investigaciones estuviesen al alcance de todos, una vez que la variedad que los incorpora hubiese sido puesta en el mercado ${ }^{19}$. Las tecnologías modernas han simplificado y acelerado los procedimientos de obtención vegetal, el uso de las características existentes, así como el desarrollo de nuevas características. Estos nuevos procedimientos facilitan el libre acceso a las características valiosas ${ }^{20}$.

Así, cualquier obtentor podría desarrollar otras variedades que tengan la misma mejora, utilizando la variedad inicial sin pagar compensación alguna al obtentor de la primera variedad. Por ello y para una mejor protección para los desarrollos de la ingeniería genética, era necesario revisar el artículo 5.3 del Acta del cupov de 1978, con la finalidad de adaptarlo a los nuevos desarrollos de la biotecnología ${ }^{21}$.

Pues bien, con el fin de adaptar el privilegio del obtentor a los nuevos desarrollos de la genética, durante la revisión de 1991 del cupov, se estableció en el artículo 15.1 inciso iii) del Acta del cupov de 1991 que los actos para el desarrollo de una variedad nueva quedan excluidos del alcance de la protección de los derechos de obtención; pero se introdujo el concepto de variedad esencialmente derivada para reforzar la protección ${ }^{22}$.

Así las cosas, se podrá seguir utilizando cualquier variedad protegida para desarrollar nuevas variedades, salvo que caiga dentro de la categoría bien delimitada de las variedades esencialmente derivadas. La naturaleza de la derivación esencial hará que el obtentor planifique muy bien la finalidad de sus experimentos de obtención; y, en caso de que obtenga una variedad esencialmente derivada, entonces deberá entablar negociaciones con el titular de la variedad original para el otorgamiento de una licencia ${ }^{23}$.

No obstante, el actual sistema de protección de variedades vegetales fomenta el uso barato -y de bajo riesgo- de las variedades vegetales existentes con características valiosas, toda vez que no se requiere el uso de grandes modificaciones al genoma

$19 \mathrm{Si}$ un obtentor desarrolla una nueva variedad vegetal resistente a una enfermedad específica y esta resistencia se debe a un gen insertado por técnicas de ingeniería genética, la nueva variedad estaría a disposición de cualquiera que quisiera mejorarla. Ibíd., p. 50.

20 Kock, Michael et al., “The Legal Protection of Plant-Biotechnological Inventions and Plant Varieties in Light of the EC Biopatent Directive", International Review of Intellectual Property and Competition Law, vol. 37, n. ${ }^{\circ}$ 2, 2006, pp. 142-143. En el pasado, el obtentor inicial gozaba de un derecho de exclusiva de 10 a 15 años a partir de la introducción en el mercado de su variedad. En la actualidad esa ventaja se ha reducido a 4-5 años. Se trata de un lapso de tiempo demasiado corto para asegurar al obtentor el adecuado retorno de las inversiones. Esta situación hace peligrar el equilibrio entre el libre acceso a los recursos genéticos y la protección efectiva de las nuevas variedades vegetales.

21 Rотн, "Current Problems in the Protection", cit., p. 55, proponía posponer la autorización de la libre utilización de la variedad hasta después de un determinado número de años de comercialización de la variedad protegida.

22 Greengrass, Barry, "The 1991 Act of the upov Convention" en European Intellectual Property Review, vol. 13, 1991, p. 471.

23 Ibíd., p. 471. Este nuevo principio en el cupov representa una extensión importante de la zona de protección de la variedad vegetal. Esta zona comprenderá en el futuro una distancia mínima de la distintividad de las variedades resultantes. 
de la variedad. Simplemente se realizan cambios genéticos de pequeña escala y la mezcla de las características ya existentes.

Por otra parte, las inversiones de alto riesgo en la búsqueda de nuevas características no se compensan porque están sometidas a la libre disposición ${ }^{24}$.

Algunos autores consideran que la solución podría ser la suspensión por un determinado período de tiempo, a partir de la concesión del título de obtención vegetal, de la libre disposición de las variedades por otros obtentores con el propósito de desarrollar nuevas variedades, o permitir la disposición mediante el pago de un canon razonable. Incluso si se decide que solamente se debería permitir con respecto a las semillas depositadas en el Registro de Variedades ${ }^{25}$.

Ante lo limitado del derecho de protección de obtención vegetal y las dificultades para ejercer los derechos de obtención vegetal por vía judicial, los obtentores están desarrollando métodos biológicos para obtener una protección ilimitada de la propiedad industrial contenida en sus variedades vegetales. Un ejemplo es la tecnología de los híbridos que predomina en el maíz, la caña de azúcar y algunos otros vegetales. Las variedades híbridas poseen muchas ventajas, no solamente para el obtentor, sino también para el agricultor. La heterosis produce híbridos de alta producción y resistencia a los factores ambientales. Además, la tecnología de los híbridos otorga al obtentor una protección de facto, porque el agricultor no puede hacer uso del producto de la cosecha para siembra y es muy difícil utilizar su germoplasma como fuente de variación inicial para el privilegio del obtentor. Los críticos de la tecnología híbrida dicen que el vigor híbrido se puede obtener con variedades estables ${ }^{26}$.

Otra solución es la tecnología de protección del germoplasma denominada "terminator" que hace que la semilla sea estéril, lo que asegura una protección contra la copia. Los agricultores critican esta tecnología porque les impide hacer uso del privilegio del agricultor.

Ahora bien, no solamente los mejoradores gozan de un privilegio, también lo hacen los agricultores, quienes pueden sembrar el producto de la cosecha.

\subsection{Privilegio del agricultor}

La mayoría de los países en vías de desarrollo tienen una economía agrícola orientada-principalmente- hacia los mercados locales y que depende en gran medida de las semillas producidas por los pequeños agricultores de variedades "tradicionales" y "mejoradas", que estos mantienen y siguen adaptando a las condiciones locales.

Los denominados sistemas de semillas de los agricultores se refieren principalmente a los métodos de que se valen los agricultores para producir, obtener, mantener y elaborar las semillas y distribuirlas de una estación de cultivo a la siguiente y

24 Kock et al., “The Legal Protection of Plant-Biotechnological”, cit., p. 143.

25 Ibíd., p. 143.

26 Ibíd., p. 143. 
de un agricultor a otro. Cada año se seleccionan las plantas de elevado rendimiento, buena calidad y gran adaptabilidad, y con el tiempo se va produciendo -voluntaria o involuntariamente- un mejoramiento lento y gradual del rendimiento de la variedad. Mediante la introducción de un sistema de protección de las variedades vegetales, el sistema de semillas de los agricultores se va transformando en un sistema formal de semillas ${ }^{27}$. Por tanto, se hace necesario reglamentar el uso, por parte de los agricultores, del producto de la cosecha ${ }^{28}$.

En las versiones del cupov de 1961, 1972 y 1978 se permitía a los agricultores sembrar el producto de la cosecha sin pagar regalías al titular del derecho de la obtención. Este privilegio se basa en una de las principales prácticas de los agricultores y se estimó que debía ser reconocido por los derechos de obtención vegetal, permitiendo que los agricultores pudieran sembrar la semilla sin tener que pagar nada por ello. De modo que los agricultores no tenían que preocuparse por la introducción de los derechos de obtención vegetal ${ }^{29}$. En el Acta del cupov de 1978, conservar la semilla con este propósito no era considerado un acto de infracción ${ }^{30}$.

Pero en el Acta del cupov de 1991, con la extensión de los actos sujetos a autorización del titular de los derechos de obtención, cualquier acto de utilización del material de propagación o de la semilla sin autorización del titular es un acto de infracción, con independencia de su propósito ${ }^{31}$.

Como contrapartida, el artículo 15.2 del Acta del cupov de 1991 permite a los Estados miembros establecer una excepción en favor de los agricultores, respetando los legítimos intereses del obtentor de la variedad. Un Estado miembro

27 Van Wijk, Jeroen, Aplicación de la protección de las variedades vegetales Simposio OMPI-UPOv sobre los Derechos de Propiedad Intelectual en el ámbito de la biotecnología vegetal, Ginebra, 24 de octubre de 2003.

28 El examen del origen del privilegio del agricultor debe comenzar por la legislación norteamericana sobre obtenciones vegetales, ya que, como se verá a continuación, la PVPA podría considerarse precursora de la regulación de este privilegio. En efecto, el epígrafe 2543 de la PVPA contiene dos excepciones a los derechos otorgados por un certificado de obtención vegetal que podrían equipararse al privilegio del agricultor. En particular, se trata de la Farmer's exception t de la Crop exemption.

Así, mientras la Farmer's exception permite al agricultor conservar el excedente de su cosecha con la finalidad de volver a plantarlo en sus instalaciones, la Crop exemption autoriza al agricultor para vender el excedente de su cosecha a otros agricultores, con la condición de que estos últimos no la propaguen posteriormente. No obstante, para evitar que los agricultores entren en competencia directa con el titular de la protección, se exige en ambos casos que quienes se benefician de estas excepciones no se dediquen principalmente a la producción comercial de semillas. Ver SÁnchez Gil, Olga, "La ley española de protección de obtenciones vegetales, a la luz de la última reforma del Convenio upov de 19 de marzo de 1991", Actas de Derecho Industrial, t. XviI, 1996, pp. 344-346.

29 Llewelyn, Margaret, "The legal protection of Biotechnological inventions", European Intellectual Property Review (EIPR), vol. 18, n.o 3, 1997, p. 124.

30 Verma, “Trips and Plant Variety Protection”, cit., p. 285.

31 Ibíd., p. 285. El artículo 14.1 del Acta del cupov de 1991 extiende la protección del material de propagación de la variedad a cualquier producción, reproducción, multiplicación, acondicionamiento con propósitos de propagación, oferta en venta, venta u otras formas de comercialización, exportación importación o almacenamiento con cualquiera de los propósitos anteriores, requerirán autorización previa del obtentor. Al extender el alcance de la protección a todo tipo de actos, el privilegio del agricultor debía quedar establecido de forma expresa. Greengrass, “The 1991 Act”, cit., p. 469. 
podrá restringir el derecho del obtentor en relación con cualquier variedad, con objeto de permitir a los agricultores utilizar el producto de la cosecha obtenido en sus propias plantaciones con fines de propagación en esas mismas plantaciones. Así pues, se permite la práctica de guardar las semillas, pero con la diferencia de que estará sujeta a que el Estado miembro desee autorizar la excepción ${ }^{32}$.

La implantación de esta disposición legal asegura que los países velarán por los derechos de los obtentores al momento de ejercer esta opción. Cabe esperar que los Estados miembros examinen la aplicación de esta disposición especie por especie ${ }^{33}$.

Mediante la nueva disposición legal el derecho para guardar las semillas queda sujeto a ciertas condiciones. Como se ha indicado antes, el artículo 17.2 del Acta del cupov de 1991 concede a los Estados miembros la posibilidad de restringir los derechos de los obtentores por causas de interés público. Este derecho queda condicionado a que los titulares del derecho de obtención reciban una remuneración equitativa ${ }^{34}$.

En la propia Acta del cupov de 1991 se establece que no se pretende conceder un derecho general a los agricultores, sino que los países establecerán en qué casos procede conceder el privilegio del obtentor. En esta dirección apunta la advertencia hecha por la Conferencia Diplomática de 1991: el artículo 15.2 del Acta del cupov de 1991 no va en el sentido de extender el privilegio del agricultor a sectores de la agricultura o la horticultura donde no es una práctica común ${ }^{35}$.

El reconocimiento expreso del privilegio del agricultor en el cupov, representa un paso adelante. Sin embargo, se deben establecer ciertos límites que salvaguarden los derechos de los obtentores. El resultado será que no todos los Estados miembros harán uso de esta excepción, incluso se podrá prohibir en defensa de los legítimos intereses de los obtentores ${ }^{36}$.

32 Verma, “trip's and Plant Variety Protection”, cit., p. 285 y Greengrass, “The 1991 Act”, cit., p. 469. El análisis del tratamiento del privilegio del agricultor por esta regulación nos lleva a constatar que se trata de una figura de marcado carácter político, tan es así que la propia adopción de esta figura bajo la forma de una "excepción facultativa" persiguió la adhesión de nuevos miembros a la upov, pues las dificultades políticas derivas de la extensión de la protección hasta el producto final habrían sido insalvables de no haberse optado por una excepción de tipo obligatorio. Ver Sánchez Gil, Olga, "El privilegio del agricultor y la excepción en beneficio del agricultor de la Ley 3/2000", en La propiedad Industrial sobre obtenciones vegetales y organismos transgénicos, Valencia, Tirante lo Blanch, 2007, p. 347.

33 El lenguaje utilizado satisfizo a los círculos interesados durante el proceso legislativo. Durante la Conferencia Diplomática del cupov de 1991 se recomendó formalmente que el artículo 15.2 del Acta del cupov de 1991 no debía entenderse como un intento de extender el privilegio del agricultor a sectores de la agricultora en los cuales no era usual. Ver Greengrass, “The 1991 Act”, cit., p. 469.

34 Esto quiere decir que si los Estados miembros quieren adoptar el privilegio del agricultor tendrán que concederle al titular del derecho de obtención una compensación equitativa. Ver Llewelyn, “The legal protection”, cit., p. 124.

35 Correa, Carlos, "Biological resources and Intellectual property rights", European Intellectual Property Review, vol. 14, n. ${ }^{\circ}$ 5, 1992, p. 156.

36 Ibíd., p. 156. 
Ahora bien, el derecho del obtentor también finaliza una vez que este ha puesto la variedad vegetal en el mercado; esto es: se agota su derecho sobre la variedad vegetal.

\subsection{Agotamiento del derecho del obtentor}

El derecho del obtentor no se extenderá a actos sobre la variedad protegida una vez que esta haya sido puesta en el mercado por el obtentor o por un tercero con su consentimiento, a menos que: implique un acto de propagación de la variedad; implique un acto de exportación del material de la variedad que permita su explotación en un país que no otorgue protección al género o especie botánica de la variedad, salvo que se exporte el material para consumo final ${ }^{37}$.

El derecho del obtentor se extiende extraordinariamente si lo comparamos con el concedido al titular de un derecho de patente. Esta amplitud es necesaria debido a las características de las variedades vegetales y justifica ciertas especialidades en relación al agotamiento del derecho de monopolio otorgado al obtentor.

En este sentido debe tenerse en cuenta que, debido a la susceptibilidad de reproducción de las variedades vegetales, el derecho del obtentor no puede agotarse con la mera comercialización del producto protegido porque supondría la libre circulación de un material que puede ser susceptible de sucesivas reproducciones, debilitando de esta manera la exclusiva del obtentor. En este punto se observa una clara diferencia con el derecho de patentes: el titular de una patente ve agotado su derecho cuando el producto protegido por la patente ha sido puesto en el mercado por el titular o por un tercero con su consentimiento. En consecuencia, el titular no podrá prohibir la fabricación del mismo puesto que en ello radica precisamente la exclusiva otorgada al inventor sobre la nueva regla técnica puesta en el mercado ${ }^{38}$.

\subsection{LÍMITE TEMPORAL}

El último límite que analizaremos será el límite temporal. Así, el artículo 19 del Acta del cupov de 1991 aumenta la duración de la duración de los derechos del obtentor, pasando, de un mínimo de 18 años en el caso de vides y árboles y 15 en el caso de otras especies, a períodos de 25 y 20 años respectivamente. La extensión del período a 20 años hace que en la mayor parte de los Estados miembros la duración de un derecho de obtención vegetal sea similar al de las patentes ${ }^{39}$.

37 Por tanto, el derecho del obtentor de impedir la reproducción de la variedad es inagotable. Ver Greengrass, "The 1991 Act”, cit., p 471.

38 Curto Polo, "Las protecciones de las invenciones biotecnológicas", cit., pp. 23662367.

39 Greengrass, “The 1991 Act”, cit., pp. 471-472. 


\section{LOS LÍMITES DEL ÁMBITO DE PROTECCIÓN DE LOS DERECHOS de obtención Vegetal en la Ley Federal de Variedades Vegetales}

Como todo derecho, la propiedad no es omnímoda. A este respecto el artículo 27 constitucional restringe la propiedad privada a las modalidades que dicte el interés público. Si bien el artículo 28 constitucional establece que no se consideran monopolios los privilegios temporales concedidos a los inventores (en este caso por analogía desarrolladores de nuevas variedades) para que este derecho de exclusiva no afecte la libre concurrencia al mercado, ni frustre el desarrollo de nuevas variedades, ni sea un obstáculo para la producción de la variedad. A continuación se presentan, en la tabla 2, los límites que impone la LFVV a los derechos de los obtentores.

\section{TABLA 2}

LÍMITES A LOS DERECHOS DEL TÍTULO DE OBTENCIÓN VEGETAL

\begin{tabular}{|l|l|}
\hline \multirow{2}{*}{ Actos excluidos de la protección } & Actos de uso privado \\
\cline { 2 - 2 } & Excepción de experimentación \\
\cline { 2 - 2 } & Privilegio del agricultor \\
\hline Agotamiento del derecho del obtentor & No se encuentra regulado en la LFVV \\
\hline Límites por interés público & No se encuentra regulado en la LFVV \\
\hline Límite temporal & 15 y 18 años según sean perennes o no \\
\hline Límite territorial & La República Mexicana \\
\hline Licencias obligatorias & Por emergencia \\
\cline { 2 - 2 } & Por falta de explotación \\
\hline
\end{tabular}

\section{I. Actos EXCLUIDOS DE LA PROTECCIÓN DEL TítULO DE OBTENCIÓN VEGETAL}

En primer lugar se analizan los actos que no se contemplan en el derecho de exclusiva conferido al obtentor por la fracción II del artículo 4 LFVV, a saber, la excepción de experimentación, los actos de uso privado y el privilegio del agricultor.

La fracción I del artículo 5 LFVV contiene la excepción de experimentación: no se requiere autorización del obtentor para utilizar la variedad vegetal como fuente de investigación, para el mejoramiento genético de otras variedades vegetales.

Esta excepción no se puede equiparar con el privilegio del mejorador. Este privilegio no solo abarca el desarrollo de nuevas variedades sin la autorización del obtentor de la variedad inicial, sino que también permite la explotación comercial de la nueva variedad vegetal sin autorización del obtentor. Este privilegio no se contempla en la legislación mexicana de obtenciones vegetales. 
La ausencia del privilegio del mejorador en la LFVV es más que criticable. Este privilegio es una de las características del sistema de protección de obtenciones vegetales, que lo hacen más adecuado que el sistema de patentes para fomentar la innovación en el sector de las variedades vegetales.

No obstante, los actos con fines de experimentación no son los únicos que están excluidos del derecho del obtentor en la LFVV, también lo están los actos de uso privado de la variedad vegetal.

Las fracciones II y III del artículo 5 LFVV configuran la excepción del uso privado, con una fórmula de redacción sumamente casuística y alambicada. En efecto, la fracción II del artículo 5 LFVV establece que no se aplicarán los derechos del obtentor a la multiplicación de la variedad vegetal para "uso propio como grano de consumo". La fracción III del mismo artículo establece la no aplicabilidad de los derechos del obtentor para "el consumo humano o animal que beneficie exclusivamente a quien lo lleva a cabo".

La redacción de esta excepción, además de ser obscura y rebuscada, no contempla el caso de variedades vegetales ornamentales, porque estas ni se consumen, ni son granos. Podría utilizarse una fórmula más sencilla para este límite: los derechos de obtención vegetal no se extenderán a los actos llevados a cabo con carácter privado y con fines no comerciales. Mediante esta fórmula tan sencilla se abarcan infinidad de situaciones y se evita la casuística tan particular de la LFVV.

La fracción II del artículo $5 \mathrm{LFvV}$ establece que no se requiere el consentimiento del obtentor de una variedad vegetal para utilizarla en la multiplicación del material de propagación, siempre y cuando sea para uso propio como grano para siembra, de conformidad con el Reglamento de la Ley Federal de Variedades Vegetales (RLFVv) y las normas oficiales mexicanas que establezca la Secretaría de Agricultura, Ganadería Pesca y Alimentación (sagarpa).

El artículo 8 RLFVV establece que el privilegio del agricultor sólo corresponderá a personas físicas y que estará restringido a la cantidad de material de propagación que el productor agrícola guarde (o reserve) para sembrar una superficie, que no exceda los límites establecidos en las normas oficiales mexicanas correspondientes.

Esta regulación es muy imprecisa puesto que no se establece la obligación de utilizar el material de la variedad en la explotación propia y tampoco se salvaguardan los intereses del obtentor. Además, la exigencia de que el agricultor deba ser persona física es algo inusual. Entendemos que la intención del legislador era evitar que las grandes sociedades que se dedican a la explotación comercial puedan beneficiarse del privilegio, pero deja fuera a los ejidos, que son personas morales también. Por último, nunca se promulgó la Norma Oficial Mexicana en la que -según el RLFvvse deben establecer los límites de superficie del privilegio ${ }^{40}$. pp. 97-98. 
Pues bien, los actos que se han analizado pueden efectuarse sin el consentimiento del obtentor. No obstante existe otro límite - no contemplado por la LFVV- que se produce por el ejercicio del derecho, esto es, el agotamiento.

\subsection{Ausencia del agotamiento Del Derecho de obtentor}

El Acta del cupov de 1978 no contempla el agotamiento de los derechos del obtentor. Esta ausencia se subsanó mediante el artículo 16 del Acta del cupov de 1991 que establece que el derecho del obtentor no se extenderá a los actos relativos al material de su variedad que haya sido vendido o comercializado de otra manera en el territorio de la Parte Contratante, por el obtentor o con su consentimiento, o al material derivado de dicho material, a no ser que esos actos impliquen una nueva reproducción o multiplicación, o bien impliquen exportación del material de la variedad a países que no concedan protección a esa misma variedad.

En el caso mexicano, y aunque la LFVV sigue en muchos aspectos el Acta del cupov de 1991, respecto del agotamiento se siguió el Acta del cupov de 1978. Esta situación debe remediarse, mediante la adopción de una regulación del agotamiento, armonizada con el Acta del cupov de 1991. Esta opinión se basa en dos motivos: el primero es que el titular de la variedad podría acaparar de un modo absoluto el mercado, puesto que teóricamente cualquier persona quedaría impedida de comercializar y distribuir la variedad aun cuando se la hubiera adquirido al obtentor.

El segundo motivo es evitar la asimetría con el sistema de patentes. En efecto, la fracción vi del artículo 22 LPI establece que el derecho que confiere una patente sobre productos que consistan en materia viva no producirá efecto alguno contra un tercero que ponga en circulación -o comercialice- los productos patentados, para fines que no sean de multiplicación o propagación, después de que estos hayan sido introducidos lícitamente en el comercio por el titular de la patente o su licenciatario ${ }^{41}$.

\subsection{AusenCia de límites por INTERés Público}

Otra de las ausencias notables, y más tratándose de un tema concerniente a la agricultura, son los límites por interés público. Solamente encontramos en el artículo 4 RLFVV que los derechos que la LFVV y el propio RLFVV otorgan a los obtentores se ejercerán libremente, "sin más limitaciones que las conducentes para la protección de la biodiversidad".

Aunque la protección de la biodiversidad puede considerarse de interés público, estimamos que la LFVV no regula absolutamente los límites por interés público. A la luz del derecho comparado, podemos considerar que esta situación es anómala. En efecto, el artículo 9.1 del Acta del cupov de 1978 establece que el libre ejercicio de

41 Magaña Rufino, José Manuel, Derecho de la propiedad industrial en México, 2. ed., México, Porrúa, 2014, pp. 18-20. 
los derechos de obtención sólo podrá limitarse por razones de interés público. De este modo, el Acta del cupov de 1978 deja abierta la posibilidad de que puedan establecerse este tipo de límites.

A guisa de ejemplo, el artículo 13.8 del Reglamento CE 2100/1994 de Protección Comunitaria de Variedades Vegetales (RCPOv) preceptúa -con todo aciertoque el ejercicio de los derechos conferidos por la protección comunitaria de las obtenciones vegetales no podrá infringir ninguna de las disposiciones dictadas por motivos de orden público, seguridad pública, protección de la salud y de la vida de las personas y de los animales o vegetales, protección del medio ambiente, protección de la propiedad industrial o comercial, o con vistas a preservar la competencia o el comercio o la producción agrícola ${ }^{42}$.

El legislador mexicano debe hacer uso de la autorización del Acta del cupov de 1978 e incluir en la LFVV una limitación de los derechos de obtención por motivos de interés público. Esto, con objeto de evitar que la limitación por interés público quede como una mera declaración de buenas intenciones; proponemos así que la LFVV contemple un procedimiento para declarar que la explotación de una variedad vegetal atenta contra el interés público.

Llegados a este punto, entraremos en el estudio de los límites más obvios de cualquier derecho: los límites territorial y temporal.

\subsection{LÍMITES TERRITORIAL Y TEMPORAL}

Con respecto al límite territorial, acá solamente corresponde señalar que la LFvV es una ley de carácter federal, por lo que su aplicación se extiende a todo el ámbito geográfico de la República Mexicana.

En punto al límite temporal, el legislador mexicano sigue los parámetros del Acta del cupov de 1978. Por ende, el título de la obtención vegetal mexicano tiene una vigencia de dieciocho años -contados a partir de la fecha de expedición del título- para especies perennes (forestales, vides, frutícolas y ornamentales) y de quince años -a partir de la fecha de expedición del título- para las demás especies. Transcurrido el plazo para el que fue concedido, el título de obtentor quedará sin efecto. Consiguientemente, la variedad vegetal, su aprovechamiento y su explotación pasarán al dominio público. Se trata, en todo caso, de plazos improrrogables (art. 4 fracc. II incs. a) y b) LFvV).

En fin, los límites a los derechos del obtentor que hemos visto restringen el ejercicio de tales derechos de un modo absoluto. Empero, existe otra limitación que, si bien no restringe el ejercicio de los derechos de obtención de forma directa, obliga al titular de la variedad vegetal a permitir que terceras personas realicen los actos comprendidos en su derecho de exclusiva: se trata de las licencias obligatorias.

42 Para ampliar sobre el rcpov, ver Quintana Carlo, Ignario, "El Reglamento CE Número 2100/1994 relativo a la protección comunitaria de las obtenciones vegetales", Actas de Derecho Industrial, t. xvi, 1995, pp. 81-107. 


\section{Licencias obligatorias de Un TÍtulo de obTención VEGETAL}

El artículo 9.2 del Acta del cupov de 1978 establece que cuando se limite el ejercicio de los derechos del obtentor para asegurar la difusión de la variedad, el Estado miembro de la upov deberá adoptar todas las medidas necesarias para que el obtentor reciba una remuneración equitativa. De acuerdo con estas prescripciones, la LFVV prevé que se concedan licencias obligatorias por circunstancias de emergencia y por falta de explotación, obligando -en tales casos- a retribuir al obtentor.

\section{I. LICENCIAS OBLIGATORIAS POR EMERGENCIA}

El artículo 25 LFVV prevé que existirán circunstancias de emergencia cuando la explotación de una variedad vegetal se considere indispensable para satisfacer las necesidades básicas de un sector de la población y exista deficiencia en la oferta o abastecimiento.

Cabe señalar que las licencias obligatorias por emergencia no son novedosas en el derecho mexicano de la propiedad industrial. En la antigua legislación de patentes de la -abrogada- Ley de Invenciones y Marcas de 1975 se preveía la concesión de licencias no voluntarias bajo el nombre de "licencias de utilidad pública", en circunstancias no del todo diferentes a las que se establecen en el artículo $25 \mathrm{LFVV}^{43}$.

El artículo $42 \mathrm{RLFVV}$ viene a colmar una laguna de la LFvV mediante la regulación de la declaración de emergencia. Según el citado precepto, la SAGARPA - previa opinión favorable de la Secretaría de Economía- determinará si imperan circunstancias extraordinarias en una región (o en todo el país), que afectan la satisfacción de las necesidades básicas de un sector de la población; y si existe riesgo de que se impida, entorpezca o encarezca la producción, prestación o distribución, con la consecuente deficiencia en la oferta o abastecimiento, que se resolvería en todo o en parte mediante la explotación de una o más variedades protegidas. Esta declaración de emergencia deberá ser publicada en el Diario Oficial de la Federación.

Una vez declarada la emergencia, la SAGARPA iniciará el procedimiento para conceder una licencia no voluntaria a terceros, distintos del titular de la obtención vegetal. En cualquier caso, se deberá dar oportunidad al titular de la variedad vegetal para que él mismo satisfaga la demanda y que permita hacer frente a las circunstancias de emergencia a que se refiere la LFVv. Según el artículo 43 RLFVV, si el obtentor manifiesta interés en solventar o participar en la situación de emergencia, lo comunicará a la Dirección General de Agricultura - de la SAGARPA- dentro de los cinco días hábiles siguientes a la fecha en que reciba la notificación correspondiente.

Sólo en caso de que el titular de la variedad no esté en condiciones de hacer frente a la emergencia, conforme a la invitación de la SAGARPA, se procederá al

43 Rangel Ortiz, Horario, "La protección de las variedades vegetales en el Derecho Mexicano", Actas de Derecho Industrial, t. XIx, 1998, p. 149. 
otorgamiento de una licencia no voluntaria; esto es, de una licencia de emergencia a favor de la persona que esté en condiciones de producir lo necesario durante la circunstancia de emergencia. Según el artículo 44 RLFVv, la concesión de las licencias por emergencia se hará a través de licitación pública, según los procedimientos y requisitos establecidos en la Ley de Adquisiciones y Obras Públicas.

Es menester señalar que entre las condiciones del otorgamiento de una licencia de emergencia se incluye la obligación a cargo del licenciatario de pagar una compensación al titular del derecho de la obtención vegetal. Por último, la LFVV establece que al concluir el plazo para el que fue otorgada la licencia de emergencia, el titular de la variedad vegetal recuperará plenamente sus derechos (art. 26 fraccs. III y IV).

Así las cosas, la LFVv cumple con la obligación que impone el Acta del cupov de 1978 de garantizar una remuneración equitativa al obtentor, aunque se debe señalar que presenta algunos aspectos que es necesario remediar.

Por una parte, la LFVV solamente menciona, como causa de emergencia, la necesidad de contar con la suficiente cantidad de producto para abastecer las necesidades de un sector de la población. No contempla el caso de que la producción de la variedad vegetal sea de primordial importancia para la salud pública, la defensa nacional o el medio ambiente. Y tampoco contempla que la falta de explotación o la insuficiencia la explotación implique graves perjuicios para el desarrollo económico o tecnológico del país. Situaciones que también pueden calificarse de emergencia y que es conveniente que se incorporen a la LFVV.

Por otra parte, el artículo $28 \mathrm{LFVV}$ prevé que las licencias obligatorias por emergencia sean de carácter exclusivo, salvo que la gravedad y magnitud de la emergencia hagan imposible que un solo licenciatario haga frente a la misma. Si se parte de la base de que las licencias obligatorias tratan de mitigar los efectos del monopolio del titular de la variedad sobre la producción de la misma, no se entiende por qué se conceda otro monopolio a un tercero distinto del obtentor. Por ende, las licencias obligatorias por emergencia en México deben ser no exclusivas.

Pues bien, las situaciones de emergencia no son las únicas bajo las cuales se pueden conceder licencias obligatorias en el derecho mexicano. Este tipo de licencias forzosas se pueden conceder también por falta de explotación de la variedad.

\subsection{LICENCIAS OBLIGATORIAS POR FALTA DE EXPLOTACIÓN}

El segundo párrafo del artículo 25 LFVV establece otra modalidad de las licencias no voluntarias, conocidas como licencias obligatorias por falta de explotación. El citado precepto señala que, en caso de que la variedad vegetal no se hubiere explotado en un plazo de tres años, contados a partir de la fecha de expedición del título de obtención vegetal, se procederá como si existiese una situación de emergencia.

De ahí la obligación de explotar la variedad vegetal amparada por un título de obtentor dentro de los tres años siguientes a la expedición del título. Su in- 
cumplimiento se traduce en exponer el derecho exclusivo conferido por el título de obtentor a la imposición de una licencia obligatoria por falta de explotación.

$\mathrm{Al}$ igual que en el caso de las licencias obligatorias por emergencia, en este supuesto deberá darse oportunidad al titular de la variedad vegetal de producir la variedad amparada por su título de obtentor, a los fines de surtir el mercado. Las licencias obligatorias por falta de explotación se tramitarán de la misma forma que las licencias obligatorias por emergencia, según dispone el segundo párrafo del artículo $25 \mathrm{LFvV}^{44}$.

Se debe advertir que la LFvv no prevé su concesión a instancia de parte. Esta omisión debe resolverse, puesto que en la práctica es difícil que la SAGARPA actúe de oficio y licite este tipo de licencias.

\section{Conclusiones}

La estructura dicotómica de la agricultura en México, es decir, campesina-tradicional y moderna, hace necesario analizar los límites a los derechos de obtención vegetal. En efecto, como parte de las obligaciones que adquirió México en el TLCAN está la de proteger la propiedad industrial en variedades vegetales. Como se ha señalado, el TLCAN es el punto culminante del cambio de modelo de desarrollo agropecuario en el país operado en la última parte del siglo pasado.

Dentro de las limitaciones que establece la LFVV se encuentran la excepción de uso privado, la excepción de experimentación y el privilegio del agricultor. Es criticable que no se haya incorporado el privilegio del mejorador, que -a diferencia de la excepción de experimentación- permite utilizar la variedad vegetal obtenida sin licencia del titular de la que le dio origen. El privilegio del agricultor se encuentra regulado de forma imprecisa y deficiente. Se han aportado propuestas de reforma legal para que cumplan mejor su función de equilibrio entre los intereses de obtentores y agricultores.

No solamente se han encontrado regulaciones imprecisas, sino que hay ausencias importantes. La LFVV no contiene una regulación del agotamiento, ni de los límites por interés público. En punto al agotamiento, es urgente regularlo porque podría ocasionar una grave distorsión en el mercado al no agotarse el derecho con la adquisición de manera legal al obtentor o su representante; además genera una asimetría con el derecho de patentes que sí contempla el agotamiento. Por lo que respecta a los límites por interés público, es necesaria una formulación general, más allá de la protección de la biodiversidad. En efecto, como se ha apuntado al inicio del presente trabajo, la agricultura dicotómica de nuestro país requiere de límites a los derechos de obtención para proteger a la agricultura campesina.

Por último, en lo que concierne a las licencias por emergencia y por falta de explotación, si bien la LFVV contiene regulación al respecto, requiere de una me- 
jora legal para evitar mejor los efectos dañinos de un monopolio mal utilizado. La regulación de las licencias por emergencia únicamente para el abasto de determinada variedad a un sector de la población. No contempla los casos de que sea de importancia para la salud pública, la defensa nacional o el medio ambiente. De otro lado, las licencias por falta de explotación no pueden ser concedidas a instancia de parte, situación que limita la posibilidad de implementarlas.

\section{BibliografíA}

Arcudia Hernández, Carlos. "El régimen de protección jurídica de las obtenciones vegetales en México: propuestas para una mejor adaptación al sistema cupov", Revista La Propiedad Inmaterial n. ${ }^{\circ}$ 19, 2015, pp. 89-112.

Arcudia Hernández, Carlos. "El privilegio del agricultor. Análisis de la legislación europea y su aplicación al caso mexicano", Revista Propiedad Intelectual n..$^{\circ}$ 17, 2014, pp. 83-104.

Becerra Ramírez, Manuel. "La ley Mexicana de Variedades Vegetales", Liber ad Honorem Sergio García Ramírez, México, unam, 1998, pp. 115-140.

Coll-Hurtado, Atrántida y Godínez Calderón, María de lourdes. La agricultura en México: un atlas en blanco y negro, México, Instituto de Geografía UNAM, 2003.

Cordera, Rolando y Tello, Carlos. La disputa por la Nación, México, Siglo XXI, 2010.

Correa, Carlos. "Biological resources and Intellectual property rights", European Intellectual Property Review, vol. 14, n.o 5, 1992, pp. 154-157.

Curto Polo, Mercedes. "La protección de las invenciones biotecnológicas (Especial referencia a la coexistencia de patentes y títulos específicos en relación a las obtenciones vegetales)", Revista General de Derecho, año LIv, n. ${ }^{\circ} 642$, 1992, pp. 2353-2395.

Gattari, Carlos y Durante, Martha. "Comentarios sobre la Ley Federal de Variedades Vegetales de los Estados Unidos Mexicanos”, en Temas de Derecho Industrial y de la Competencia n. ${ }^{\circ}$ 2, Buenos Aires, Ciudad Argentina, 1997, pp. 299-316.

GreEngrass, BARry. “The 1991 Act of the upov Convention”, European Intellectual Property Review, vol. 13, 1991, pp. 466-472.

Ibarra Muñoz, David. Ensayos sobre economía Mexicana, México, Fondo de Cultura Económica, 2015.

Kock, Michael et al. "The Legal Protection of Plant-Biotechnological Inventions and Plant Varieties in Light of the EC Biopatent Directive", International Review of Intellectual Property and Competition Law, vol. 37, n. 2 2, 2006, pp. 135-155.

Magaña Rufino, José Manuel. Derecho de la Propiedad Industrial en México, 2. ${ }^{\mathrm{a}}$ ed., México, Porrúa, 2014. 
Puyana, Alicia y Romero, José. México, de la crisis de la deuda al estancamiento económico, México, El Colegio de México, 2009.

Quintana Carlo, Ignario. "El Reglamento CE Número 2100/1994 1994 relativo a la protección comunitaria de las obtenciones vegetales", en Actas de Derecho Industrial, t. XVI, 1995, pp. 81-107.

Rangel Ortiz, Horario. "La protección de las variedades vegetales en el Derecho Mexicano", en Actas de Derecho Industrial, t. xIx, 1998, pp. 127-167.

Roth, Benhard. "Current Problems in the Protection of Inventions in the Field of Plant Biotechnology. A position paper”, en International Review of Intellectual Property and Competition Law, vol. 18, n. ${ }^{\circ} 1,1987$, pp. 41-55.

SÁnchez Gil, Olga. "El privilegio del agricultor y la excepción en beneficio del agricultor de la Ley 3/2000", en La propiedad industrial sobre obtenciones vegetales y organismos transgénicos, Valencia, Tirante lo Blanch, 2007, pp. 337-358.

SÁnchez Gil, Olga. "La ley española de protección de obtenciones vegetales, a la luz de la última reforma del Convenio upov de 19 de marzo de 1991", en Actas de Derecho Industrial, t. XVII, 1996, pp. 219-259.

VAN WijK, Jeroen. "Aplicación de la protección de las variedades vegetales", en Simposio OMPI-Upov sobre los Derechos de Propiedad Intelectual en el ámbito de la biotecnología vegetal, Ginebra, 24 de octubre de 2003.

Verma, Surinder. "Trips and Plant Variety Protection in Developing Countries", European Intellectual Property Review, vol. 16, n. ${ }^{\circ}$ 6, 1995, pp. 281-289.

Yúnez Naude, Antonio, 2010, "Las transformaciones del campo y el papel de las políticas públicas", en Historia económica general de México, México, El Colegio de México, pp. 729-756. 